\title{
Spina bifidada kalça sorunları
}

\author{
Hip problems in spina bifida
}

\author{
Ayşegül Bursalı1 ${ }^{1}$, Timur Yıldırım² \\ 1Ortopedi ve Travmatoloji Uzmanı, Özel Hekim \\ ${ }^{2}$ S. B. Metin Sabancı Baltalimanı Kemik Hastalıkları Eğitim ve Araştırma Hastanesi, Ortopedi ve Travmatoloji Kliniği, İstanbul
}

\begin{abstract}
Nöral tüp defektlerinin bir parçası olan spina bifada, sinir sistemini olduğu kadar kas iskelet ve diğer organ sistemlerini de etkileyerek, bireyin hayat boyu engelli olmasına yol açan önlenebilir bir konjenital hastalıktır. Omurgada etkilenen seviyeye bağlı olarak alt ekstremitede duyu kayıplarını da içeren gevşek paralizi gözlenir. Spina bifidalı hastaların hareket kabiliyetlerini birincil olarak nörosegmental seviye etkilese de, yaş, kognitif seviye, eklem kontraktürleri ve instabiliteleri, pelvik ve omurga sorunları diğer etkenlerdir. Spina bifidalı hastaların takibinde kontraktür ve eklem deformitelerinin önlenmesi ilk basamağı oluşturur. Bu amaçla germe egzersizleri ve pozisyonlamaya yenidoğan döneminde başlanmalı ve aile bu konunun önemi hakkında bilinçlendirilmelidir. Spina bifidada etkileri karşılanmayan kas grupları zamanla deformite gelişimine neden olurlar. Özellikle lumbar seviyeli hastaların çalışan adduktor ve fleksör kaslarına karşın abduktor ve ekstansör güçlerinin olmaması, paralitik kalça çıkıklarına yatkınlığa neden olur. Kalça sorunlarının cerrahi tedavisinde amaç kalça çevresi kas dengesinin tekrar oluşturulması ve bunu yaparken ilave eklem sertliklerine neden olunmamasıdır.
\end{abstract}

Anahtar sözcükler: spina bifida; miyelomeningosel; eklem instabilitesi, kalça; kas transferi; paralitik çıkık
Part of the neural tube defects, spina bifida is a preventable congenital disease, not only affecting the neural system but also the muscular and the other organ systems, causing lifetime disabilities. Depending on the level of the involvement of spine, flask paralysis with sensory deficits can be observed in lower extremities. Although the neurosegmental level being the main predictor for the ambulatory abilities of these patients; age, cognitive functions, joint contractures and instabilities, pelvic and spine disorders can also affect these. Main purpose of the follow-up for these patients is to prevent joint contracture and deformities. For that reason, stretching exercises and positioning must begin in infantile ages and families must be enlightened for the importance of rehabilitation. Muscles left without antagonists can cause deformities. Especially in patients with lumbar level involvement, overactive hip adductor and flexor muscles with weak hip abductor and extensor power can be a predisposition for the paralytic hip dislocations. The aim of the treatment for the hip disorders is to achieve muscle balance around the hip joint without causing additional joint contractures.

Key words: spina bifida; myelomeningocele; instability, hip; muscle transfer; paralitic dislocation

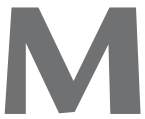

iyelodisplazi veya miyelomeningosel kas iskelet sistemini olduğu kadar genitoüriner, gastrointestinal ve kognitif fonksiyonları da etkileyerek, bireyin hayat boyu sakatlığına yol açan karmaşık, doğumsal bir hastalıktır. Miyelodisplastik defekt, embriyolojik gelişim esnasında, gestasyonun 28. gününden önce nöral tüpün kaudal ucunun kapanmasında oluşan eksiklikten kaynaklanır. Miyelomeningoselli hastaların şant uygulamaları ile hidrosefali gelişiminin kontrolü ve etkili üriner sistem tedavileri sayesinde sağkalım oranlarının artması, kas-iskelet sistemi tedavilerine olan ihtiyacı arttırmıştır. Miyelomeningoselin etiyolojisi halen tam olarak aydınlatılamamasına karşın, genetik ve çevresel nedenlerin birlikte etkilediği multifaktöryel kaynaklı olduğuna inanılmaktadır. Bilinen en önemli etiyolojik neden gebe kadınlarda folik asit yetersizliği olup, bu eksiklik başta miyelomenigosel olmak üzere diğer nöral tüp defektlerinin nedeni olarak bilinmektedir. Hamilelik öncesi günlük $400 \mu \mathrm{g}$ ile başlanan folik asit desteği sayesinde spina bifida gelişiminin \%70-100 oranında önlenebileceğine dair kanıtlar vardır. ${ }^{[1,2]}$ Miyelomeningoselde genetik etmenlerin de etkili olduğu görülür. Anne veya babada nöral tüp

- Illetişim adresi: Doç. Dr. Ayşegül Bursalı, Yıldız Posta Caddesi, Emekli Subay Evleri Sitesi, 34. Blok, No: 5/1, Gayrettepe, İstanbul Tel: 0212 - 2746135 e-posta: bursaliaysegul@gmail.com

- Geliș tarihi: 3 Eylül $2014 \quad$ Kabul tarihi: 3 Eylül 2014 
defekti olması spina bifida görülme oranını \%3'e, kardeşlerden birinde olması \%3-8'e çıkarır. ${ }^{[3]}$

Prenatal tarama araçları, anensefali ve miyelomeningosel görülme oranını önemli oranda azaltmıştır. Tarama amacıyla maternal serum alfa-fetoprotein (AFP) ve yüksek çözünürlüklü ultrasonografi (US) yöntemleri kullanılır. AFP testi fetal miyelomeningosel taramasında kullanılan biyokimyasal bir metod olmasına karşın, duyarlılık ve özgüllüğünün düşük olması rutin klinik kullanımı açısından sorun yaratabilir. Yüksek çözünürlüklü US ile \%94'e yakın kesinlik elde edilebilir. ${ }^{[4]}$ Yurtdışında etkili tarama programları ve gebelik öncesi folat kullanımı ile nöral tüp defektlerinin (NTD) önemli ölçüde azaltılmasına karşın, ülkemizde tarama ile saptanan gebeliklerde gebeliğin sonlandırılmasına karşı olan kültürel direnç ve folat kullanımı hakkında toplumsal bilincin oluşmamış olması NTD'lerin halen büyük bir toplumsal sağlık sorunu olarak devam etmesine neden olmaktadır.

\section{MIYELOMENINGOSELDE DOĞAL SEYIR}

Miyelomeningoselli hastalarda gelişebilecek sakatlığın şiddeti ve yürüme potansiyeli, nörosegmental seviye ile yakından ilişkilidir. Nörolojik tutulum seviyesinin tespiti için ilk önerilen ve günümüzde halen en sık kullanılan, Sharrard'ın bildirdiği, fonksiyon gösteren en alt motor seviyeye bağlı olan sınıflama sistemidir. ${ }^{[5]}$ Sharrard nörosegmental seviyeleri; torasik, üst lumbar, alt lumbar ve sakral seviye olmak üzere dörde ayırmıştır. Torasik seviyeye sahip çocuklar paraplejiktir, gövde kaslarında değişken derecede innervasyon görülür. Üst lumbar seviyeli çocuklarda aktif kalça fleksiyon ve adduksiyonu vardır. Alt lumbar seviyeli çocuklar aktif diz ekstansiyonu ve ayak dorsifleksiyonu, sakral seviyeli çocuklar ise değişken derecelerde aktif ayak bileği plantar fleksiyonu ve aktif parmak fleksiyonu yapabilirler. Nörosegmental seviyenin belirlenmesi, fiziksel fonksiyonların, deformite gelişim riskinin ve oluşabilecek komplikasyonların tahmininde yardımcı olur.

\section{NÖROSEGMENTAL SEVIYEYE ÖZGÜ SORUNLAR VE YÜRÜME POTANSIYELLERI}

Miyelomeningoselli hastaların yürüme kapasitelerini etkileyen en önemli etmen nörosegmental seviyeleridir. Kaudal seviyeden kraniyale yükseldikçe yürümenin kalitesi azalır, yürüme için gerekli enerji tüketimi ve yürümeye yardımcı cihazların boyutları artar. Yürümeyi etkileyen diğer etmenler ise; yaş, kognitif düzey, alt ekstremite deformitesi ve instabiliteleri, eklem kontraktürleri, oturabilme, pelvik oblisite, geçirilen kırıklar, spastisite gelişmesi, şant ve omurga sorunları olarak sayılabilir. ${ }^{[6,7-10]}$

\section{Torasik seviye}

Torasik seviyeli miyelomeningoselli hastalar paraplejiktir. Bu çocukların kalçalarında zaman içinde sıklıkla abduksiyon, dış rotasyon ve fleksiyon, dizlerinde fleksiyon ve ayak bileklerinde plantar fleksiyon deformitesi gelişir. Çocuklukta ayakta durma sehpaları ve gövde korseli yürüme cihazları ile dik dursalar da zamanla tekerlekli sandalyeye bağımlı kalırlar. Buluğ çağında toplum içi yürüme oranlarının değişik çalışmalarda \%0-33 arasında olduğu bildirilmiştir..$^{[9,11-13]}$

\section{Üst lumbar seviye}

Üst lumbar seviyeli hastalarda belirgin olan deformite, kalça ve dizin sabit fleksiyon kontraktürüdür. Bu hastalarda kalça fleksörleri ve biraz da adduktorları çalışır. Kalça abduktor ve ekstansör güçleri olmadığı için, çalışan kasların antogonistlerce karşılanmaması zamanla kalça çıkığına neden olur. Yürüme potansiyelleri torasik seviyeli hastalarınkine benzer. Erişkin çağda toplum içi ambulasyonu devam eden hasta oranı değişik çalışmalarda \%10-54 arasında verilmiştir. ${ }^{[9,11-13]}$

\section{Alt lumbar seviye}

Üst lumbar seviyede belirtilen kaslara ilave olarak daha fazla adduktor güçleri, mediyal hamstring ve daha önemlisi diz ekstansiyon güçleri bulunur. Aktif kuadriseps gücü varlığı miyelomeningoselli hastaların yürüme kapasitelerini göstermesi açısından kilit rol oynar. Değişken düzeyde tibialis anterior güçleri bulunur. Tibialis anterior gücü karşılanmadığında pes kalkaneus deformitesi gelişebilir. Bu çocuklar diz altı ortezler ile mobilize olabilirler. Ancak kalça abduktor ve ekstansörlerinin çalışmaması nedeniyle abduktor topallaması vardır ve ideal olarak koltuk değneği kullanmaları önerilir. Bu hastalar, kalça çevresi kas güçlerinin dengesiz olması nedeniyle, ilerleyici kalça subluksasyonu ve çıkığı gelişmesi açısından yükssek risk altındadırlar. ${ }^{[9,11-13]}$

\section{Sakral seviye}

Sakral seviye lezyonu olan spina bifidalı hastaların yaklaşık \%90'ı ergen dönemde de toplum içi ambulatuvar kalmaya devam ederler. Kalça ve diz çevresi kas dengesi daha iyidir. Ancak, ayak seviyesinde değişken derecelerde fleksör güce sahiptirler. Parmaklarda pençeleşme, kavus ayak ve rocker bottom deformitesi görülebilir. Ayak deformiteleri nedeniyle ayak ülserasyonları sık görülür.

\section{KALÇA SORUNLARI}

Miyelomeningoselli hastaların kalça sorunları; yumuşak doku kontraktürleri, kemik deformiteleri, kalça instabiliteleri, çıkık ve yarı çıkıklarını kapsar. 


\section{Yumuşak doku kontraktürleri}

\section{Fleksiyon kontraktürü}

Sabit kalça fleksiyon kontraktürleri miyelomeningoselde sık rastlanan sorunlardandır. Torasik ve üst lumbar seviyeli hastalarda görülme sıklığı çok yüksektir. Kalça fleksör gücünün ekstansörler tarafindan karşılanamaması sonucu gelişir. Tek başına olabileceği gibi adduksiyon veya dış rotasyon ve abduksiyon kontraktürü ile birlikte de bulunabilir.

Fleksiyon kontraktürü lumbar lordozun artışı ile dengelenmeye çalışılır, ancak kontraktür $30^{\circ}$ 'yi geçtiğinde ortez kullanmayı, yüzükoyun yatmayı güçleştirir. Asimetrik kontraktürler pelvik oblisiteye ve oturma dengesinin bozulmasına neden olabilir. Kontraktür gelişiminin önlenmesi için germe egzersizleri ve pozisyonlama önem taşır. $30^{\circ}$ 'yi geçen kontraktürlerin cerrahi yolla açılması gerekir.

\section{Abduksiyon-dış rotasyon kontraktürü}

Kalçanın dış rotasyon kontraktürü alt ekstremitesinde innervasyonu olmayan hastalarda daha sık görülür. Çoğu zaman uygun olarak pozisyonlanmayan veya kötü pozisyonlanan çocuklarda zaman içinde gelişir. Fleksör aktivitesi olan çocuklarda abduksiyondış rotasyon kontraktürüne fleksiyon kontraktürü de eklenebilir. Uzun süreli oturma fleksör komponentin oluşmasını kolaylaştııı. Tensör fasya latanın da kontraktüre katılımı ile diz fleksiyon kontraktürü tabloya eklenir.

\section{Kemik deformiteleri}

Miyelomenigoselde kemik deformiteleri sabit kontratürlere ve kas dengesizliğine bağlı olarak gelişir. Koksa valga ve aşırı anteversiyon sıklıkla görülür. Femur başının asetabular rime basısına bağlı asetabular deformite gelişebilir.

\section{Kalça instabiliteleri, yarı çıkık ve çıkıkları}

Spina bifidaya bağıı kalça çıkıkları teratolojik olabileceği gibi, iliopsoas ve adduktor gücün karşılanamamasına bağlı olarak (paralitik) da ortaya çıkabilir. Carrol ve Sharrard miyelomeningoselli yenidoğanların \%46'sında, Beeker ve Scheers ise \%22'sinde kalça instabilitesi olduğunu tespit etmişlerdir. ${ }^{[14,15]}$

Samuelsson ve Eklof'un ergen döneme kadar tedavi edilmemiş hastaların pelvis röntgenleri üzerinde yaptığ araştırmada torasik seviyede \%60, L1-L2 seviyesinde $\% 40$, L3 seviyesinde $\% 66$ ve L4 seviyesinde $\% 62$ oranında kalça çıkık ve yarı çıkık bildirilmiştir. Yazarlar, L5 ve sakral seviyede çıkık kalça tespit etmemişler ancak sırasıyla \%41 ve \%11 oranında yarı çıkık bildirmişlerdir. ${ }^{[16]}$

\section{TEDAVi HEDEFLERi}

Miyelomeningoselli hastaların kalça sorunlarının, özellikle de alt lumbar seviyenin paralitik çıkıklarının nasıl tedavi edileceği tartışmalı bir konu olmayı sürdürmektedir. 1960'larda Sharrard'ın öncülük ettiği, açık redüksiyon ve iliopsoasın trokanter majora naklini savunan yaklaşım başlangıçta geniş kabul görmüş, ancak daha sonra oluşturduğu ikincil kontraktürler, eklem sertlikleri ve patolojik kırıklar nedeniyle sorgulanır olmuştur. Miyelomeningoselin tedavisinde temel hedef, koruyucu tedbirlerin alınması olmalıdır; bunlar, hastanın mobilitesini etkileyebilecek ayak, diz, kalça ve omurga deformitelerinin önüne geçebilmelidir. Bu amaçla spina bifidalı hastalar daha yenidoğan döneminde iken uygun rehabilitasyon programına alınarak gerekli pozisyonlama ve germe teknikleri hakkında aile eğitimine tabi tutulmalıdırlar. Paraliziye bağlı gelişen kontraktürler ve kalça instabiliteleri ise hastaya ek morbidite vermeksizin tedavi edilmelidir. Miyelomeningoselli hastaların ayakta dikilmelerinin veya yürümelerinin potansiyel yararları; üst ekstremitenin güçlenmesi, kemik yoğunluğunun artması, kontraktürlerin önlenmesi, obezitenin önlenmesi ve daha önemlisi çocuk ve aileye vereceği motivasyon olarak sayılabilir.

\section{KONTRAKTÜRLERIN TEDAVISi}

Kalça eklem deformitelerinin önlenmesi ve tedavisine yenidoğan döneminde başlanmalıdır. Kalça fleksör, abduktor veya adduktorlarının uygun programlarla esnetilmesi ve pozisyonlaması ile kontraktür gelişimi önlenebilir. Esnetme programlarına gece kullanılan ortezler yardımcı olabilir. Ortez ile ayak bilekleri nötral dorsifleksiyonda, diz ve kalçalar ekstansiyonda, kalça eklemleri $30^{\circ}$ derece abduksiyonda tutulmalıdır. Tedavi uygulanmayan çocuklarda, çocuğun büyümesi sırasında kontratürler gelişmeye başlar. İleri kontraktürler, ortez kullanımına engel teşkil ettiği için, cerrahi yolla tedavi edilmelidir. Kalça fleksör gevşetme sırasında; rektus femoris, sartorius, tensor fasya lata, iliopsoas ve anterior eklem kapsülü dahil tüm anterior kontrakte yapılar gevşetilmelidir. Fleksiyon kontraktürüne abduksiyon kontraktürü de eşlik ettiğinde, lateralde yer alan fibrotik abduktor kaslar ve kısa dış rotatorlar da gevşetmeye eklenebilir. Ameliyat sonrası uzun bacak alçısı uygulanması ve günlük 12 saat prone pozisyonda yatırılması tavsiye edilir. Azami yumuşak doku gevşetmesine karşın istenilen ekstansiyon derecesine erişilemeyen durumlar$\mathrm{da}$, femur proksimalinden ekstansiyon osteotomisi uygulanması gerekli olabilir. ${ }^{[17]}$ 


\section{KALÇA INSTABILITESI, ÇIKIK VE YARI ÇIKIKLARININ TEDAVISi}

Miyelomeningoselde kalça deformitesinin miktarı, nörolojik seviyeye bağımlıdır. Kalça deformitesinin tedavisi, nörolojik seviyeye, gelişen deformitenin özelliğine ve hastanın fonksiyonel seviyesine bağlı olarak değişir.

Torasik seviye ve üst lumbar miyelomeningoselli hastaların kalça çevresinde motor ve duyu kayıpları bulunur. Çoğu zaman fizyoterapi sırasında ortezler ile ambule olurlar ve nadiren on yaşından sonra mobilizasyonları devam eder. Oturma ve yürümeleri için kalçaların yerine yerleştirilmesi gerekmez. Ancak kontraktür varlığında uygun tedavi yöntemleri ile tedavileri gerekir. Cerrahi sonrasında da eklem sertliklerinin oluşmaması için tedbir alınması gerekir.

Orta lumbar seviyeli miyelomeningoselli hastaların kalça instabilitelerinin cerrahi tedavisi açısından günümüzde tartışmalar sürmektedir. Bu seviyedeki lezyonların tedavisinde, açık redüksiyon, tendon gevşetmeleri veya transferleri, femoral ve/veya pelvik osteotomileri içeren tedavi seçeneklerinin biri veya kombinasyonlarını kapsayan tedavi yöntemleri tanımlanmıştır. Sharrard, orta lumbar seviyeli hastaların büyük çoğunluğunda ilerleyici kalça instabilitesi geliştiği ve bunun yürüme fonksiyonlarını etkileyeceği ön görüsü ile, proflaktik olarak da iliopsoas tendon transferiyle tedavi edilmeleri gerektiğini bildirmiştir. ${ }^{[18]}$ Sharrard'ın tanımladığı bu teknikte, iliopsoas tendonu iliak kanatta açılan delikten geçirilerek trokanter majora nakledilir.
Bu sayede iliopsoasın fleksör etkisi zayıflar, trokanter majora nakli ile kalça ekstansör ve abduktoru olarak rol almaya başlar. Erken dönem takiplerinde kalçanın radyolojik sonuçlarına katkı gösterdiği gösterilmesine karşın, uzun dönemde yürüme analizi ile yapılan çalışmalarda fonksiyonlar üzerine kontrol grubundan farklı bir etkisi gösterilememiştir.

Kalça stabilitesi ve abduktor güç temininde transferi uygulanan diğer bir kas M. obliquus externus abdoministir. Genellikle adduktorların gevşetilmesi veya iskiuma transferi ile kombine edilmiştir. Adduktor transferi ile kalça ekstansiyon gücünün arttırılması ve adduktor deforme edici güçlerin azaltılması hedeflenir. Phillips ve Lindseth, bu transfere üçüncü bir ilave olarak tensor fasya latanın gluteus maksimusa naklini ekleyerek, kalça çevresi güçlerin daha dengeli hale getirildiğini belirtmişlerdir (Şekil 1, 2). Bu tedavi uygulanan 41 hastanın 37 'sinde yürüyüş paterninin düzeldiği ve breys ihtiyacının azaldığını belirtilmiştir. ${ }^{[19]}$

Kas transferlerine ait potansiyel sorunlar; transferle hedeflenen abduktor güce ulaşılamaması, kalça çevresi eklem sertliklerinin oluşabilmesi, immobilizasyon ve eklem sertlikleri ile ilişkili kırıklar sayılabilir. Tendon transferi sırasında, yumuşak doku girişimlerine ek olarak uygulanacak kemik müdahaleleri, uygulamanın başarı şansını arttırır.

Herhangi bir kas transferi uygulanmaksızın açık redüksiyon, kapsülorafi ve osteotomileri (femoral ve/ veya) içeren sınırlı sayıda literatür bilgisi de bulunmaktadır. Weisl ve arkadaşları, bu yolla iliopsoas transferini

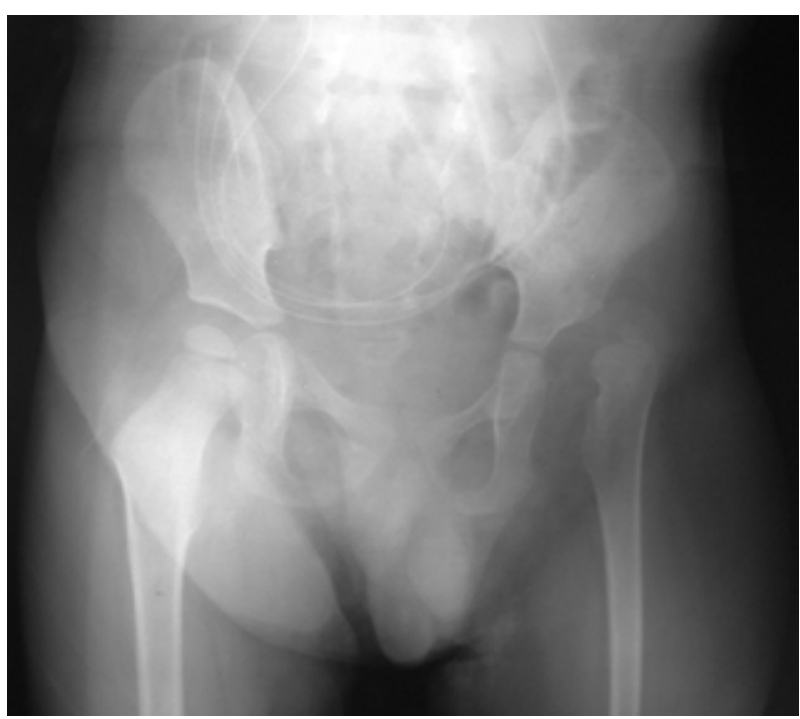

Şekil 1. L4 seviyeli sol kalça çıkığı olan üç yaş altı aylık erkek hastanın pelvis ön-arka grafisi.

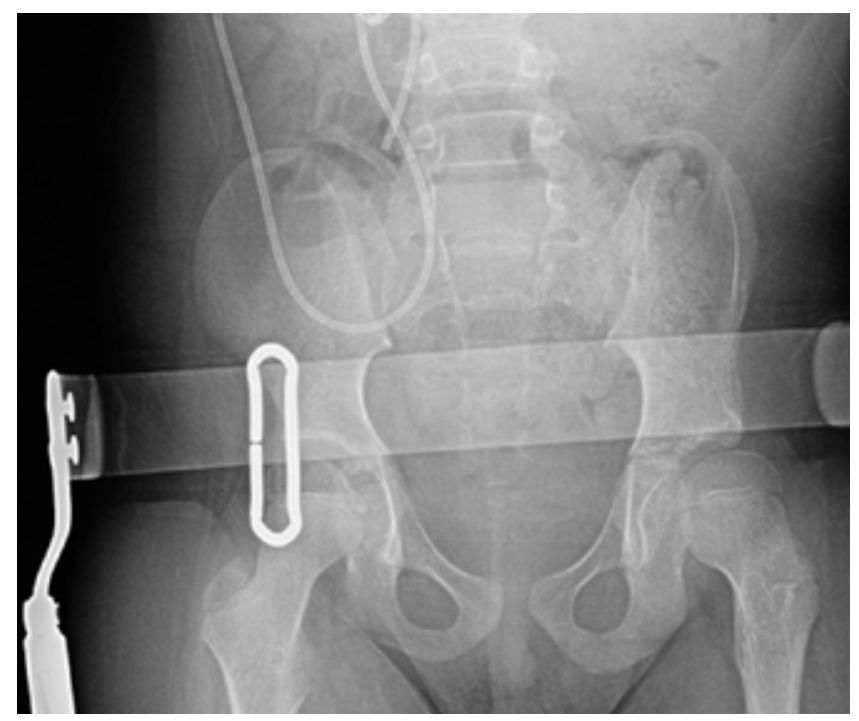

Şekil 2. Phillips ve Lindseth'in tariflediği üçlü kas transferi uygulanan hastamızın ameliyat sonrası beşinci yıl ayakta pelvis ön-arka grafisi. 
karşılaştırdıkları çalışmada fonksiyonel açıdan farkııık bulmamışlardır. ${ }^{20]}$ Ancak bu konuda uzun dönem sonuçlar henüz literatürde yer almamaktadır.

Sakral seviyeli kalça instabiliteri, torakal ve lumbar seviyeye göre çok daha az sıklıkta görülürler. Bu hastaların kalça abduktor ve ekstansörleri güçleri korunmuştur; tedavileri gelişimsel kalça displazisi benzeri yapılmalıdır.

\section{KAYNAKLAR}

1. Czeizel A, Dudas I. Prevention of the first occurrence of neuraltube defects by periconceptional vitamin supplementation. $\mathrm{N}$ Engl J Med 1992;327(26):1832-5.

2. Prevention of neural tube defects: results of the Medical Research Council Vitamin Study. MRC Vitamin Study Research Group. Lancet 1991;338(8760):131-7.

3. Luo J, Nye JS. Evidence for Genetic Etiologies of Neural Tube Defects. In: Sarwark JF, Lubicky JP, eds. Caring for the child with spina bifida. Rosemont, Illinois: American Academy of Orthopaedic Surgeons; 2001:43-64.

4. Babcook CJ. Ultrasound evaluation of prenatal and neonatal spina bifida. Neurosurg Clin N Am 1995;6(2):203-18.

5. Sharrard WJ. The segmental innervation of the lower limb muscles in man. Ann R Coll Surg Engl 1964;35:106-22.

6. Bartonek A, Saraste H. Factors influencing ambulation in myelomeningocele: a cross-sectional study. Dev Med Child Neurol 2001;43(4):253-60.

7. Flanagan A, Gorzkowski M, Altiok H, Hassani S, Ahn KW. Activity level, functional health, and quality of life of children with myelomeningocele as perceived by parents. Clin Orthop Relat Res 2011;469(5):1230-5. CrossRef

8. Bartonek A, Saraste H, Samuelsson L, Skoog M. Ambulation in patients with myelomeningocele: A 12-year follow-up. J Pediatr Orthop 1999;19(2):202-6.
9. Samuelsson L, Skoog M. Ambulation in patients with myelomeningocele: a multivariate statistical analysis. J Pediatr Orthop 1988;8(5):569-75.

10. Diaz Llopis I, Bea Muñoz M, Martinez Agulló E, López Martinez A, García Aymerich V, Forner Valero JV. Ambulation in patients with myelomeningocele: a study of 1500 patients. Paraplegia 1993;31(1):28-32.

11. Asher $\mathrm{M}$, Olson J. Factors affecting with the ambulatory status cystica of patients with spina bifida cystica. J Bone Joint Surg Am 1983;65(3):350-6.

12. Desouza LJ, Carroll N. Ambulation ofbraced myelomeningocele patient. J Bone Joint Surg Am 1976;58(8):1112-8.

13. Charney EB, Melchionni JB, Smith DR. Community ambulation by children with myelomeningocele and highlevel paralysis. J Pediatr Orthop 1991;11(5):579-82.

14. Carroll NC, Sharrard WJ. Long-term follow-up of posterior iliopsoas transplantation for paralytic dislocation of the hip. J Bone Joint Surg Am 1972;54(3):551-60.

15. Beeker TW, Scheers MM. The hip joint in spina bifida accompanied by myelomeningocele: a review of the cases of a spina bifida team. Neuro Orthopedics 1986:2:87-94.

16. Samuelsson L, Eklöf $\mathrm{O}$. Hip instability in myelomeningocele: 158 patients followed for 15 years. Acta Orthop Scand 1990;61(1):3-6.

17. Feiwell E. Surgery of the hip in myelomeningocele as related to adult goals. Clin Orthop Relat Res 1980;(148):87-93.

18. Sharrard WJ. Posterior iliopsoas transplantation in the treatment of paralytic dislocation of the hip. J Bone Joint Surg $\mathrm{Br}$ 1964;46:426-44.

19. Phillips DP, Lindseth RE. Ambulation after transfer of adductors, external oblique, and tensor fascia lata in myelomeningocele. J Pediatr Orthop 1992;12(6):712-7.

20. Weisl H, Fairclough JA, Jones DG. Stabilisation of the hip in myelomeningocele. Comparison of posterior iliopsoas transfer and varus-rotation osteotomy. J Bone Joint Surg $\mathrm{Br}$ 1988;70(1):29-33. 